University of Nebraska - Lincoln

DigitalCommons@University of Nebraska - Lincoln

Faculty Publications from Nebraska Center for Research on Children, Youth, Families, and Schools
Children, Youth, Families \& Schools, Nebraska Center for Research on

2013

\title{
The Efficacy of Conjoint Behavioral Consultation on Parents and Children in the Home Setting: Results of a Randomized Controlled Trial
}

\author{
Susan M. Sheridan \\ University of Nebraska-Lincoln, ssheridan2@unl.edu \\ Ji Hoon Ryoo \\ University of Virginia, jr3gv@virginia.edu \\ Andrew Garbacz \\ University of Oregon, andy.garbacz@wisc.edu \\ Gina M. Kunz \\ Nebraska Center for Research on Children, Youth, Families, and Schools, gkunz2@unl.edu \\ Frances L. Chumney \\ Western Georgia University, fchumney@westga.edu \\ Follow this and additional works at: https://digitalcommons.unl.edu/cyfsfacpub \\ Part of the Child Psychology Commons, Counseling Psychology Commons, Developmental \\ Psychology Commons, Family, Life Course, and Society Commons, and the Other Social and Behavioral \\ Sciences Commons
}

Sheridan, Susan M.; Ryoo, Ji Hoon; Garbacz, Andrew; Kunz, Gina M.; and Chumney, Frances L., "The Efficacy of Conjoint Behavioral Consultation on Parents and Children in the Home Setting: Results of a Randomized Controlled Trial" (2013). Faculty Publications from Nebraska Center for Research on Children, Youth, Families, and Schools. 95.

https://digitalcommons.unl.edu/cyfsfacpub/95

This Article is brought to you for free and open access by the Children, Youth, Families \& Schools, Nebraska Center for Research on at DigitalCommons@University of Nebraska - Lincoln. It has been accepted for inclusion in Faculty Publications from Nebraska Center for Research on Children, Youth, Families, and Schools by an authorized administrator of DigitalCommons@University of Nebraska - Lincoln. 
Published in Journal of School Psychology 51:6 (2013), pp. 717-733; doi: 10.1016/j.jsp.2013.09.003

Copyright $\odot 2013$ Society for the Study of School Psychology. Published by Elsevier Ltd. Used by permission.

Submitted October 30, 2012; revised September 25, 2013; accepted September 25, 2013.

\title{
The Efficacy of Conjoint Behavioral Consultation on Parents and Children in the Home Setting: Results of a Randomized Controlled Trial
}

\author{
Susan M. Sheridan, ${ }^{1}$ Ji Hoon Ryoo, ${ }^{2}$ S. Andrew Garbacz, ${ }^{3}$ Gina M. Kunz, ${ }^{1}$ \\ and Frances L. Chumney ${ }^{4}$
}

1. Nebraska Center for Research on Children, Youth, Families, and Schools, USA

2. University of Virginia, USA

3. University of Oregon, USA

4. Western Georgia University, USA

Corresponding author-Susan M. Sheridan, email ssheridan2@unl.edu

\begin{abstract}
The present study is a large-scale randomized trial testing the effects of a family-school partnership model (i.e., Conjoint Behavioral Consultation, $\mathrm{CBC}$ ) for promoting behavioral competence and decreasing problem behaviors of children identified by their teachers as disruptive. CBC is a structured approach to problem solving that involves consultants, parents, and teachers. The effects of CBC on family variables that are commonly associated with important outcomes among school-aged children (i.e., family involvement and parent competence in problem solving), as well as child outcomes at home, were evaluated. Participants were 207 children with disruptive behaviors from 91 classrooms in 21 schools in kindergarten through grade 3 and their parents and teachers. Results indicated that there were significantly different increases in home-school communication and parent competence in problem solving for participants in the $\mathrm{CBC}$ relative to control group. Likewise, compared to children in the control group, children in the CBC group showed significantly greater decreases in arguing, defiance, noncompliance, and tantrums. The degree of family risk moderated parents' competence in problem solving and children's total problem behaviors, teasing, and tantrums.
\end{abstract}


Keywords: family-school partnership, conjoint behavioral consultation, disruptive behaviors, family disadvantage, randomized controlled trial

\section{Introduction}

Children with behavioral and social-emotional problems are at high risk of long-term, pervasive problems. The Report of the Surgeon General's Conference on Children's Mental Health concluded that children's emotional and behavioral concerns are associated with significant impairment and "no other set of conditions is close in the magnitude of its deleterious effects on children and youth" (U.S. Public Health Service, 2000, p. 21).

Estimates of the number of children suffering from serious behavioral and socialemotional problems vary significantly depending on the methodology and criteria used to diagnose the disorder (Brauner \& Stephens, 2006). However, one thing is clear: the occasion of serious behavioral and social-emotional disorder in childhood is linked to a variety of long-term problems including juvenile delinquency, school drop-out, incarceration, substance use, and a host of other negative outcomes that are costly to society (Campbell, 1991; Emond, Ormel, Veenstra, \& Oldehinkel, 2007; Loeber, 1991; Ramey \& Ramey, 1998). The vast majority of children with behavioral or social-emotional concerns go untreated. Despite prevalence rates suggesting that approximately $20 \%$ of children experience a serious behavioral or social-emotional disturbance at some point in their lives (U.S. Department of Health \& Human Services, 1999), recent reports indicate that only approximately $5 \%$ receive treatment other than or in addition to medication (Simpson, Cohen, Pastor, \& Reuben, 2008). Left untreated, the gap between children demonstrating behavioral and social-emotional problems and their peers increases exponentially over the early school years.

Behaviors associated with behavioral and social-emotional problems often are manifest first in the home setting (Stormshak, Bierman, McMahon, \& Lengua, 2000). It is, therefore, not surprising that interventions supporting parents (e.g., parent training) in addressing child externalizing behaviors are common. These interventions include the Positive Parenting Program (Sanders, Cann, \& Markie-Dadds, 2003), Parent-Child Interaction Therapy (Hembree-Kigin \& McNeil, 1995), and Incredible Years (Webster-Stratton \& Hancock, 1998). However, many family interventions and parent training programs (e.g., Kazdin, 2005; Patterson, 1977; Sanders, 1999) are implemented with parents as recipients of services, rather than partners in problem solving and decision making. These programs are often delivered in a manner that is distinct from what is occurring at school; that is, none link parents to schools in effective or proactive ways. Family partnership models are childfocused approaches where families and professionals cooperate, coordinate, and collaborate to enhance opportunities and success for children and adolescents across social, emotional, behavioral, and academic domains (Downer \& Myers, 2010; Lines, Miller, \& ArthurStanley, 2011).

Efforts to create partnerships with families are grounded in ecological-systems theory (Bronfenbrenner, 1979, 1992). This theory recognizes that children learn and grow within unique and overlapping systems. Accordingly, a child's learning experiences are highly 
responsive to the quality of the interface of the home and school in relationship to one another. Thus, beyond sole consideration of the child's skills, the quality of interactions between children and caregivers within primary settings (i.e., microsystems), and the relationships of individuals and supports across social contexts (i.e., mesosystems such as homes and schools), are strong predictors of subsequent school success. Research translating ecological-systems theory to educational practice has focused on strengthening the contexts and interactions within which children learn and the delivery of partnershipbased models (Cox, 2005; Sheridan, Eagle, Cowan, \& Mickelson, 2001).

Research investigating the efficacy of family-school partnerships has demonstrated promising results for students with behavioral and social-emotional challenges. Studies testing the effects of collaborative supports between families and schools (often noted as a critical component to partnership models) utilizing single-case experimental designs demonstrated compelling outcomes related to students' behaviors (e.g., tantrums across home and school; Barry \& Santarelli, 2000). A parent-teacher collaborative team model was found to increase student engagement in classroom activities, social interactions with peers, student-initiated interactions, and academic skills (Mortier, Hunt, Desimpel, \& Van Hove, 2009). In a large-scale clinical trial, Families and Schools Together (FAST), a familycentered, process-oriented intervention that stresses relationship-strengthening and trustbuilding with families has been found superior to parent education programming in increasing academic performance, classroom behavior, and social skills (McDonald et al., 2006). Similarly, a responsive model that tailors family-school interventions based on individually-based decisions (Adolescent Transition Program and Family Check-Up; Connell, Dishion, Yasui, \& Kavanagh, 2007) was superior to a randomized matched control group in curbing the demonstration of problem behaviors among adolescents and maintaining decreased risk for delinquent outcomes over time.

Interventions that emphasize parental partnerships in decision making and behavior plan implementation show potential for lasting benefits (Taylor \& Biglan, 1998). They are particularly important for students who have or are at risk for developing behavioral problems. Services targeting behavioral problems are most effective when they involve structured, collaborative problem solving; evidence-based behavioral interventions to address child behavioral concerns; and families and schools working as partners around shared goals (Guli, 2005). Parent partnerships have been found to engender empowerment, such that the more the family participates in planning services for their children, the better they feel their children's needs are being met (Koren et al., 1997) and the more control they feel over treatment (Curtis \& Singh, 1996; Thompson et al., 1997). Programs that are aimed at helping individuals become active and competent agents of change arguably enable them to identify options from which to choose, access necessary information and supports, and make effective, self-determined decisions. Processes that create conditions for families to partner with service providers may reduce barriers to services (McKay \& Bannon, 2004) and lead to improvements in retention, satisfaction, and active participation in treatment (Hoagwood, 2005); linking such processes with high-quality, research-based treatments may amplify the potential impact of effective treatments for children and families (Hoagwood, 2005). 
One factor contributing to service-delivery gaps for children with behavioral problems is failure to effectively engage families in ways that are common in partnership models (McKay \& Bannon, 2004). One parent partnership model with emerging empirical support from several experimental single case design studies (e.g., Colton \& Sheridan, 1998; Sheridan, Kratochwill, \& Elliott, 1990; Weiner, Sheridan, \& Jenson, 1998) and at least one largescale randomized trial (Sheridan et al., 2012) is conjoint behavioral consultation (CBC; Sheridan \& Kratochwill, 2008). Conjoint behavioral consultation is a family-school partnership model focused on the attainment of student goals through (a) data-based problem solving and (b) implementation of evidence-based interventions across home and school settings. CBC is an indirect intervention where family members work as partners with school personnel (consultant and teacher) to promote children's behavioral and socialemotional competencies through collaborative problem solving, co-constructed intervention plans, defined responsibilities for plan implementation, and progress monitoring of children's goals. Throughout the CBC process, parents are provided a constructive method to become meaningfully involved in supporting their child's learning and behavior, and they are provided direct opportunities to participate meaningfully in educational problem solving (i.e., goal setting, intervention planning, and evaluation). Specifically, they are engaged as partners who take an active role in (a) identifying and defining priorities (i.e., target behaviors) for intervention, (b) exploring conditions within their environments that influence problematic behaviors, (c) selecting among evidence-based interventions and developing specific and relevant plan tactics to implement in the home setting, (d) learning and using evidence-based strategies to address behavioral problems at home, and (e) evaluating the effects of the intervention for meeting predetermined behavioral goals (Sheridan \& Kratochwill, 1992, 2008).

\subsection{Empirical support for conjoint behavioral consultation}

Research support for $\mathrm{CBC}$ has amassed over the past two decades. In a review of research on parent consultation and family interventions using the Procedural and Coding Manual of the Task Force on Evidence-Based Interventions in School Psychology (Kratochwill \& Stoiber, 2002), Guli (2005) concluded CBC was an evidence-based intervention to effectively address children's needs across home and school. Single-case research using experimental multiple baseline designs supports its efficacy for children with social-emotional (Colton \& Sheridan, 1998; Sheridan et al., 1990), behavioral (Owens, Murphy, Richerson, Girio, \& Himawan, 2008), academic (Weiner et al., 1998), and behavioral health (Lasecki, Olympia, Clark, Jenson, \& Heathfield, 2008) concerns. Positive outcomes have been demonstrated for children and families from various cultural and ethnic groups (Sheridan, Eagle, \& Doll, 2006), across medical settings (Sheridan et al., 2009) and conditions (e.g., autism; Ray, Skinner, \& Watson, 1999), and across developmental periods (e.g., Kratochwill, Elliott, Loitz, Sladeczek, \& Carlson, 2003; Sheridan, Clarke, Knoche, \& Edwards, 2006).

A randomized controlled trial (RCT) documented CBC's efficacy at ameliorating students' behavioral problems with a sample of 207 students with disruptive behaviors (Sheridan et al., 2012). Researchers reported that relative to a "business-as-usual" control group, CBC produced significantly greater gains in teacher-reported adaptive behaviors $(d=0.39)$, 
teacher-reported social skills $(d=0.47)$, and parent-reported social skills $(d=0.42)$ where $d$ is the effect size recommended for use with repeated measures (Gibbons, Hedeker, \& Davis, 1993; Morris \& DeShon, 2002). Furthermore, significantly greater gains in the parentteacher relationship were found for those who participated in the CBC group relative to controls $(d=0.47)$. Gains reported in the parent-teacher relationship partially mediated the effects of $\mathrm{CBC}$ on child behavior change attesting to its importance in effective positive changes for students at behavioral risk. However, neither outcomes for parent nor child behaviors at home were reported.

A synthesis of single case design studies conducted over four years using multiple linear regression analyses (Sheridan et al., 2001) found that a model fitting client age and symptom severity predicted school outcomes relatively well $\left(R^{2}=.425\right.$, Adjusted $R^{2}=.343$; $p=.008$ ). Younger students (ages $5-7$ ) with higher behavioral severity ratings prior to $C B C$ experienced better outcomes than those experiencing less severity and compared to older children (11 years and older) at all severity levels, highlighting the benefits of $\mathrm{CBC}$ for addressing severe behavioral problems before the middle school years. A similar study (Sheridan, Eagle, \& Doll, 2006) found that CBC yielded generally positive and sizable effects for students experiencing a range of characteristics potentially placing them at educational disadvantage (i.e., fewer than two adults in the home, low maternal education, language barriers, and low socioeconomic status).

Both family and child variables have been found to influence children's behavior and adjustment in studies evaluating children's mental health and development. Among the most robust predictors of compromised child skills (including those associated with behavioral and social-emotional adjustment) is economic disadvantage (i.e., poverty or low socioeconomic status), which predicts a host of problems with social adjustment (Magnuson \& Votruba-Drzal, 2009; McLeod \& Shanahan, 1996). Low parental education also has been identified repeatedly as a risk factor in children's development (Burchinal, Peisner-Feinberg, Pianta, \& Howes, 2002). Children who live in households with just one adult are at greatest risk of displaying delays in overall development (National Council of Welfare, 2004). These family risk factors are exacerbated when they occur in combination. Research has consistently supported a cumulative risk hypothesis positing that the number of risks early in a child's life predicts behavior problems later (Ackerman, Kogos, Youngstrom, Schoff, \& Izard, 1999; Appleyard, Egeland, van Dulmen, \& Sroufe, 2005). In addition, certain child characteristics are likely to influence a child's response to behavioral interventions. The presence of a disorder (e.g., conduct disorder, ADHD, and oppositional defiant disorder) is considered a potentially salient factor influencing a treatment's effectiveness given the propensity for students with identified disorders to continue showing maladaptive behaviors even after an intervention is implemented (Offord \& Bennett, 1994). However, the variables identified as potentially important in influencing family functioning and child adjustment (e.g., family factors pertaining to cumulative disadvantage and child factors such as age and disability) have not been studied collectively in a way that identifies their role in moderating the efficacy of $\mathrm{CBC}$ on parent or child outcomes. 


\subsection{Purpose of study}

Despite the positive findings associated with $\mathrm{CBC}$ and other collaborative family-school partnership approaches, several limitations in the research literature exist. First, little is known about the effects of $\mathrm{CBC}$ on important parental partnership outcomes (i.e., competence in problem solving; family involvement in education). Second, the only published randomized controlled trial of CBC's effects to date (Sheridan et al., 2012) reported student outcomes on standardized measures; direct student outcomes as a result of $\mathrm{CBC}$ in the home setting were not reported. Third, there was no attempt by the researchers conducting this randomized controlled trial to determine student or family variables that moderate the intervention's effects on parents or students, yielding a rather narrow understanding of the participants who represent the range of student and family characteristics typically referred for family support services.

This study was part of a larger randomized controlled trial aimed at addressing children's behavioral problems (results of school-based outcomes are reported in Sheridan et al., 2012). The purpose was to investigate the effects of CBC on outcomes specific to the home setting (i.e., family involvement, competence in problem solving, and observed disruptive behaviors). Specific research questions were as follows:

1. What is the effect of CBC on family involvement (home-school communication, home-based involvement, and school-based involvement) and parent competence in problem solving?

2. What is the effect of $\mathrm{CBC}$ on disruptive child behaviors at home (arguing, defiance, noncompliance, teasing, and tantrums)?

3. Are the effects of $\mathrm{CBC}$ on parent and child outcomes moderated by child (i.e., age and presence of disability) or family variables (i.e., cumulative risk)?

\section{Method}

\subsection{Participants}

A total of 207 children (113 in the treatment condition and 94 in the control condition) and their parents and teachers served as participants in this study. Children were identified as having disruptive behaviors by their teachers based on challenges being experienced in their classrooms, and selected on this criterion (see Recruitment). Approximately $74 \%$ of child participants were males, with an average age of $7.00(S D=1.08)$ years. Kindergarten $(25 \%)$, first-grade $(35 \%)$, second-grade $(27 \%)$, and third-grade $(13 \%)$ students were involved. An estimated $69 \%$ of child participants were reported by parents to be White/nonHispanic. Additionally, $8 \%$ were reported to be African American, 5\% were identified as Hispanic or Latino, and less than 1\% were American Indian. Finally, 13\% of respondents identified children as multi-racial/ethnic, and $5 \%$ did not specify the student's race/ethnicity. Ninety-six percent were reported by parents to have English as their primary home language; $4 \%$ had a home language of Spanish. Half (50\%) of the children met criteria for free and reduced lunch, and 35\% lived in households with a total income less than $150 \%$ 
of the poverty threshold (based on 2008 poverty thresholds and household size). Nearly one-fourth of the child sample (23\%) had only one adult residing in the home.

\subsubsection{Recruitment}

Recruitment of children began with teacher nomination, wherein teachers rank ordered the top 10 students with disruptive behaviors within their classrooms to identify a potential pool of likely candidates. The Systematic Screening for Behavior Disorders (SSBD; Walker \& Severson, 1990) rating scale and a researcher-developed screener ${ }^{1}$ were then completed by teachers for the top 5 ranked children. The researcher-developed measure was a three-item scale that assessed severity and frequency of disruptive behaviors and the need for additional intervention. Severity of disruptive behaviors and frequency of disruptive behaviors were rated separately on a 1 to 9 scale $(1=$ very mild, $9=$ very severe $)$, and need for additional intervention was rated in a 1 to 5 scale $(1=$ no need, $5=$ significant need). Students who met criteria for participation were those (a) who scored in the "elevated" or "extremely elevated" risk categories on the SSBD; (b) who were reported to exhibit disruptive behaviors on the researcher-developed scale at a moderate to very severe level (i.e., the student scored a 4 or above), moderate to very frequent level (i.e., 4 or above), or demonstrated moderate to significant need for additional services (i.e., 3 or above); or (c) who had elevated scores using both the SSBD and the researcher-developed measure.

Up to three students in a classroom who met criteria for inclusion were randomly selected to participate. Classrooms (and teachers) were randomly assigned to treatment or control conditions following teacher and parent consent to participate. The mean rating for severity of problem behaviors at baseline was $6.66(S D=1.38)$. The difference in problem severity between control $(M=6.47, S D=1.40)$ and $C B C(M=6.82, S D=1.35)$ groups was not statistically significant, $t(189)=-1.796, p=.074$. An alpha of .05 was used for all other tests of statistical significance.

\subsubsection{Parents}

Parents of children who met inclusionary criteria were contacted and invited to participate. The parents were provided information about the study and consented for their own and their child's participation. A total of $67 \%$ of the parents contacted consented for their child and themselves to participate. ${ }^{2}$ In all, 207 parents participated. Ninety percent of parent participants were women; their average age was $34.74(S D=7.79)$ years. Approximately $81 \%$ were White/non-Hispanic, 4\% were African American, 3\% were Latino, 4\% selfreported as other, and $5 \%$ did not provide this information. Four percent did not have a high school degree; $17 \%$ earned only a high school diploma (or equivalent). Thirty-one percent completed some college, $30 \%$ had a college degree, $4 \%$ had completed some graduate coursework, $8 \%$ had an advanced graduate degree, and $6 \%$ did not provide this information. See table 1 for additional parent demographic information. 
Table 1. Demographic characteristics of participants at pretest.

\begin{tabular}{|c|c|c|c|}
\hline & $\begin{array}{c}\text { Total sample } \\
(N=207)\end{array}$ & $\begin{array}{c}\text { CBC group } \\
(n=113)\end{array}$ & $\begin{array}{c}\text { Control group } \\
(n=94)\end{array}$ \\
\hline Mean (SD) Child Age ${ }^{a}$ & $6.53(1.10)$ & $6.47(1.07)$ & $6.60(1.14)$ \\
\hline Mean $(S D)$ Behavior severity $(1-9)^{a, b}$ & $6.66(1.38)$ & $6.82(1.35)$ & $6.46(1.40)$ \\
\hline Mean $(S D)$ Number of risks ${ }^{a}$ & $0.72(0.81)$ & $0.81(0.81)$ & $0.60(0.80)$ \\
\hline \multicolumn{4}{|l|}{ Child gender } \\
\hline Boys & $74 \%$ & $75 \%$ & $72 \%$ \\
\hline Girls & $26 \%$ & $25 \%$ & $28 \%$ \\
\hline \multicolumn{4}{|l|}{ Child grade ${ }^{a}$} \\
\hline Kindergarten & $25 \%$ & $25 \%$ & $25 \%$ \\
\hline First & $35 \%$ & $41 \%$ & $29 \%$ \\
\hline Second & $27 \%$ & $21 \%$ & $33 \%$ \\
\hline Third & $13 \%$ & $13 \%$ & $13 \%$ \\
\hline \multicolumn{4}{|l|}{ Child race/ethnicityc } \\
\hline White, non-Hispanic & $69 \%$ & $66 \%$ & $73 \%$ \\
\hline African American & $8 \%$ & $8 \%$ & $8 \%$ \\
\hline Hispanic or Latino & $4 \%$ & $6 \%$ & $3 \%$ \\
\hline American Indian or Alaskan Native & $1 \%$ & $1 \%$ & $0 \%$ \\
\hline Other: More than One & $13 \%$ & $16 \%$ & $10 \%$ \\
\hline Unknown & $5 \%$ & $3 \%$ & $6 \%$ \\
\hline \multicolumn{4}{|l|}{ Home language } \\
\hline English & $91 \%$ & $91 \%$ & $91 \%$ \\
\hline Spanish & $4 \%$ & $5 \%$ & $2 \%$ \\
\hline Not provided & $5 \%$ & $4 \%$ & $7 \%$ \\
\hline \multicolumn{4}{|l|}{ Risk factors ${ }^{c}$} \\
\hline Fewer than two adults in home & $24 \%$ & $26 \%$ & $21 \%$ \\
\hline Maternal education less than high school & $6 \%$ & $6 \%$ & $5 \%$ \\
\hline Income less than $150 \%$ poverty level & $35 \%$ & $39 \%$ & $31 \%$ \\
\hline \multicolumn{4}{|l|}{ Disability status } \\
\hline Students with $\geq 1$ disabilities & $56 \%$ & $52 \%$ & $61 \%$ \\
\hline Receives special education services & $16 \%$ & $13 \%$ & $19 \%$ \\
\hline Participates in out-patient counseling/treatment & $18 \%$ & $17 \%$ & $18 \%$ \\
\hline Participates in family counseling & $10 \%$ & $8 \%$ & $12 \%$ \\
\hline
\end{tabular}

Notes: a. Independent samples $t$-tests yielded no significant difference $(p>.05)$ between treatment and control groups. b. Baseline rating of severity by teachers from 1 (low) to 9 (extreme). c. Chi-square test of independence yielded no significant difference $(p>.05)$ between treatment and control.

\subsubsection{Teachers}

Ninety general education teachers of participating students served as participants. Most of the teachers (96\%) were women, and 98\% self-reported as White/non-Hispanic. The average number of years in which teachers were in their current position was $9.86(S D=9.80)$. 


\subsubsection{Consultants}

Consultants were eight master's level clinicians trained or enrolled in a school or counseling psychology graduate program, having completed on average $2.63(S D=1.69)$ years of graduate education. All were women and self-reported as White/non-Hispanic. The average age of consultants was $25.38(S D=2.07)$ years. Consultants participated in a 4-week, 64-hour, criterion-based training program wherein project leaders delivered didactic instruction on the theory and practice of CBC. Readings on CBC and evidence-based behavioral interventions, video demonstrations, role-plays, self-monitoring, and individualized supervision were the primary training strategies.

\subsection{Setting}

The setting for the current study was 90 classrooms ( 49 treatment; 41 control) in 21 schools in a moderately-sized Midwestern city and surrounding communities. CBC meetings occurred in participating schools, and interventions were delivered in home and classroom settings.

\subsection{Study variables}

The independent variable in this study was parents' and teachers' involvement in CBC with the guidance of a consultant. This involved collaborative problem solving, data-based decision making, and individualized behavioral intervention plans implemented by parents at home and teachers in school. The dependent variables in the present study were (a) measures of child behaviors in their home settings as reported by parents via daily reports (Chamberlain \& Reid, 1987), (b) parent competence in problem solving, and (c) family involvement at home, at school, and in home-school communication.

Potential family and child moderating variables were investigated, based on their presence in the CBC literature as potentially impacting its effects on child outcomes (Sheridan, Eagle, \& Doll, 2006; Sheridan et al., 2001). Specifically, cumulative risk, defined as the number of family factors potentially placing children at educational disadvantage (i.e., fewer than two adults in the home, maternal education less than high school diploma, and living on a household income less than $150 \%$ of the poverty threshold) was explored as a potential moderator of $\mathrm{CBC}^{\prime}$ s effects. Certain child variables (i.e., age and presence of disability) were likewise explored as moderators. A disability was considered present if the child had a clinical diagnosis as reported by a parent or if the child received special education services as reported by a teacher.

\subsection{Measures}

Assessments of parent outcomes (i.e., family involvement and competence in problem solving) occurred one week prior to $\mathrm{CBC}$ and again approximately 12 weeks later. Child outcomes (i.e., behaviors at home) were assessed approximately once per week over 10 weeks.

\subsubsection{Family involvement in education}

Family involvement in their child's education was measured with the Family Involvement Questionnaire-Elementary Version (FIQ-E; Manz, Fantuzzo, \& Power, 2004). The FIQ-E 
is a 46-item self-report measure assessing family involvement behaviors on a four-point Likert-type scale $(1=$ rarely, $4=$ always $)$. The FIQ-E was designed to provide a snapshot of family involvement across three dimensions (i.e., school-based involvement, home-based involvement, and home-school communication). Examples of items include "I go on class trips with my child" (measuring school-based involvement), "I arrange times at home when my child's classmates can come and play" (measuring home-based involvement), and "I talk to my child's teacher about his/her difficulties at school" (measuring homeschool communication). Analyses of this study's data at baseline reveal alpha estimates of .92 for the overall scale, .85 for home-based involvement, .81 for school-based involvement, and .90 for home-school communication. Additional research replicated a 3-factor solution with an international sample, further supporting the presence of three involvement dimensions (Garbacz \& Sheridan, 2011).

\subsubsection{Parent competence in problem solving}

Parents' competence in becoming effective problem solvers was assessed with the Parent Competence in Problem Solving Scale (PCPS; Sheridan, 2004). This eight-item self-report measure assesses parents' agreement with statements regarding their ability to effectively solve problems related to their child's educational challenges. Examples of items include "I have gathered specific information (e.g., homework finished, number of tantrums, etc.) to help me understand how my child is doing" and "I have figured out what helps my child and what does not." Each item is scored on a six-point Likert-type scale ranging from 1 (disagree very strongly) to 6 (agree very strongly). The alpha estimate for the PCPS based on this study's data was .88 at baseline.

\subsubsection{Child behavioral outcomes at home}

The Parent Daily Report (PDR; Chamberlain \& Reid, 1987) was used to evaluate the occurrence of specific disruptive behaviors at home and determine whether $\mathrm{CBC}$ had an effect on overall problem behaviors at home. The PDR is a measure of 34 behaviors (e.g., arguing and teasing) on which parents indicate whether their child has exhibited each behavior within the last $24 \mathrm{~h}$. The measure allows researchers to track both the total number of problems and specific target behaviors. All items were administered to derive a total PDR score. In addition, we identified five behaviors that aligned most closely to the majority of behaviors targeted in CBC casework: arguing, defiance, noncompliance, teasing, and tantrums. The effects of $\mathrm{BC}$ in addressing these behaviors were analyzed separately from the total scores.

PDR data were collected four times during baseline for treatment and control group participants; PDR data were collected six times during the treatment phase (or an equivalent time period for control group participants). Parents were given the option of providing responses either by phone, by email response, or by returning a paper copy of the instrument. Seventy-six percent of PDRs were collected by phone; in these cases, phone calls were made by research assistants blind to parents' treatment conditions at a time agreed upon with parents. Seventeen percent of PDRs were collected via email, and close to five percent of PDRs were collected through a combination of phone and email. PDR scores used for analyses were averages within baseline time points, calculated separately for each 
condition. At baseline, the test-retest reliabilities across four time points using the intraclass correlation coefficients for arguing, defiance, noncompliance, teasing, and tantrums were $.67, .72, .76, .79$, and .67 , respectively. All are within an accepted reliability range (Landis \& Koch, 1977).

\subsection{Procedures}

\subsubsection{Business as usual}

Students who were in classrooms that had been randomly assigned to the control condition continued to receive typical services in or out of school. Traditional supports provided in schools (e.g., office referrals, Student Assistance Teams, pull-out placements in special education classrooms) or services solicited by parents in other settings constituted "business as usual." Table 1 presents data on services received by students in both treatment and control groups. There were no differences between experimental and control groups on the proportion of children who received special education services, $\chi^{2}(1)=1.402, p=.236$; amount of time special education services received daily, $t(202)=0.94, p=.349$; or receipt of additional services for behavioral, social, or emotional problems (not including CBC), $\chi^{2}(2)=0.99, p=.609$.

\subsubsection{Conjoint behavioral consultation}

$\mathrm{CBC}$ procedures followed protocols for collaborative home-school problem-solving meetings outlined in Sheridan and Kratochwill (2008). A series of CBC meetings were facilitated by a consultant. Specifically, within each classroom, a consultant met with two to three parents and a teacher for approximately three to four conjoint consultation sessions over approximately 8 weeks. All meetings were between 45 and 60 min in length (see interview objectives in table 2).

Table 2. Objectives of small group conjoint behavioral consultation interviews.

\begin{tabular}{|c|c|}
\hline Interview & Objectives \\
\hline $\begin{array}{l}\text { Needs identification/analysis interview } \\
\text { ("building on strengths") }\end{array}$ & $\begin{array}{l}\text { - Jointly identify and define child's needs and priorities } \\
\text { in behavioral terms. } \\
\text { - Determine a primary behavior to address (target } \\
\text { behavior) for initial intervention. } \\
\text { - Collaboratively develop appropriate goals for target } \\
\text { behavior across home and school. } \\
\text { - Discuss what is happening before and after the priority } \\
\text { behavior, as well as specific patterns that occur, during } \\
\text { the focused time/setting. } \\
\text { - Jointly establish a procedure to collect baseline data } \\
\text { across settings. }\end{array}$ \\
\hline $\begin{array}{l}\text { Plan development and implementation stage } \\
\text { ("planning for success") }\end{array}$ & $\begin{array}{l}\text { Collaboratively develop a plan built upon strengths } \\
\text { and competencies to address the priority behavior } \\
\text { across home and school. } \\
\text { - Train parents and teachers in plan implementation as } \\
\text { necessary. }\end{array}$ \\
\hline
\end{tabular}


- Implement agreed-upon intervention across home and school settings.

- Make immediate modifications to plan as necessary.

- Support implementation of behavioral plan at home and school through observing, providing feedback, modeling, and troubleshooting.

- Assess immediate changes in student's behavior.

Plan evaluation stage

("checking and reconnecting")
- Determine if the goals for the priority behavior have been met.

- Discuss effective elements of the intervention plan.

- Discuss continuation/termination of plan.

- Schedule additional interview if necessary, or terminate consultation.

Note: These interview objectives are based on procedures described in Sheridan et al. (2012). Due to their sensitive nature, Needs Identification/Analysis Interviews were conducted with individual parent and teacher dyads, and a consultant. All other interviews were conducted in small groups with one teacher, parents of 2 to 3 children in the teacher's classroom, and a consultant.

The first collaborative problem-solving interview was the Needs Identification/Analysis ("Building on Strengths") Interview (based on Sheridan \& Kratochwill, 2008). The objectives of this interview were to identify the specific disruptive behaviors that would be targeted for intervention, and goals for change. Given that this session involved discussion of students' challenging behaviors and parent and teacher concerns, these interviews were conducted with individual parent-teacher pairs, rather than in small groups. Consistent with our study's purpose and inclusionary criteria, all behaviors targeted in this study were considered disruptive (e.g., noncompliance, arguing, defiance).

The second collaborative CBC meeting was the Plan Development and Implementation ("Planning for Success") Interview (based on Sheridan \& Kratochwill, 2008). This meeting involved the collaborative development of an intervention plan to address target concerns and discuss methods by which parents could implement them at home. This formal meeting was followed by consultant observations during home visits to support parents' implementation of plans with fidelity. The final interview, the Plan Evaluation ("Checking and Reconnecting") Interview (based on Sheridan \& Kratochwill, 2008) focused on evaluating the plan(s), discussing progress made toward child goals, and determining needs for plan modification or discontinuation. These final meetings were conducted in small groups with two to three parents and a teacher.

Several steps were followed to insure that the consultants maintained integrity in implementing the $\mathrm{CBC}$ process with each family in the context of the small group format. First, permanent products were generated at group meetings that were specific to each child (e.g., steps for home and school plans were documented on forms for each child, a home-school communication system unique to each child was devised, and unique data collection procedures were individualized for specific settings). Second, as consultants prepared for their meetings, case-specific plans were developed and discussed among the research leadership team, providing a mechanism for monitoring the attainment of key CBC objectives for each case. Third, consultation protocols for small group CBC meetings included checks to insure that child-specific information was shared and plans developed. 
Independent data collectors reviewed audio recordings of group meetings and scored consultants' adherence to the protocols. Finally, certain practices were instituted to promote the engagement of individual parents in meetings (e.g., pre-meeting conversations with parents as needed to review agendas and encourage parental input) and plan implementation in out-of-school settings (e.g., home visits to review strategy use within natural environments).

\subsubsection{Behavioral intervention plans}

The development of behavioral plans for each student was accomplished as a central component of the CBC process. For each student, consultants introduced a number of behavioral strategies that had empirical support and were responsive to the unique function of the specific disruptive behaviors exhibited by individual students. Specifically, four intervention classes with evidence of empirical support for reducing disruptive behaviors constituted the primary intervention strategies: (a) positive reinforcement and other consequences (e.g., attention and rewards; Moore, Waguespack, Wickstrom, Witt, \& Gaydon, 1994); (b) environmental structuring and antecedent control (e.g., structured prompts and checklists, precision requests, and rules; Musser, Bray, Kehle, \& Jenson, 2001); (c) skills training (e.g., social skills training and behavioral rehearsal; Pfiffner \& McBurnett, 1997); and $(\mathrm{d})$ reductive techniques (e.g., removing privileges and response cost; McMahon \& Forehand, 2003). Additionally, all of the interventions contained a home-school communication component such as home-school notes (McCain \& Kelley, 1994). Tactics by which parents delivered the intervention strategies were specified in a collaborative and formative fashion to accommodate differences between students and preferences of parents.

Individualized treatment manuals and protocols were developed to translate the research-based interventions into formats conducive for use in each CBC case. A published intervention book series (i.e., The Tough Kid Toolbox Jenson, Rhode, \& Reavis, 2009; The Tough Kid Social Skills Book Sheridan, 2010; and The Tough Kid Parent Book Jenson, Rhode, \& Neville, 2010) provided structure for the development of plan tactics based on the four classes of interventions that were subsequently integrated into individualized plans for each student. Based on strategies published in the Tough Kid book series, a CBC behavioral strategies toolkit, consisting of 80 different intervention plans organized by behavioral function, was developed to standardize plan tactics across cases. Individuation occurred at the level of specific reinforcers, schedules of reinforcement, and other unique elements of individualized plans implemented at home by parents.

Across participants, the most frequently used plan tactic used in home settings was positive consequences and reinforcement, which were incorporated into $97 \%$ of cases. This tactic was followed by antecedent control strategies, which were represented in $66 \%$ of parent-implemented programs. Skill building was a part of $25 \%$ of home interventions, and reductive techniques were included least often, with only $11 \%$ employing them as part of the home-based package. ${ }^{3}$

Consultants used several strategies to support parents and teachers as they implemented behavioral intervention plans. In addition to the intervention manuals and protocols provided as part of individualized casework, they modeled strategy delivery and communicated via phone calls and email to provide ongoing support (see Swanger-Gagné, 
Garbacz, \& Sheridan, 2009). Likewise, families received an average of one home visit by consultants (range $=0$ to 4 ) to help parents determine methods for integrating behavioral plans into their daily routines, ensure parents' understanding of plan tactics, and hone their skills at plan implementation.

\subsection{Fidelity assessments}

Fidelity (i.e., adherence) of the $\mathrm{CBC}$ meeting procedures and fidelity with which parents implemented behavioral plans at home were assessed using a multi-method procedure.

\subsubsection{Fidelity of $C B C$ meeting procedure}

A CBC Objectives Checklists (Sheridan et al., 2001) was used to assess adherence with which consultants followed the objectives of $\mathrm{CBC}$. Each $\mathrm{CBC}$ interview consisted of specific objectives defining accuracy of delivery by consultants. The Needs Identification/Needs Analysis (Building on Strengths), Plan Development and Implementation (Planning for Success), and Plan Evaluation (Checking and Reconnecting) Interviews consisted of 20, 10, and 10 objectives, respectively. Trained, independent coders listened to 94 (45\%) of the entire sample of interviews conducted (211), selected randomly to represent each CBC stage equally, and coded the presence of each objective on the checklists. Close to $20 \%$ of these interviews were coded by two observers to assess interrater agreement.

\subsubsection{Fidelity of behavior plan implementation}

The fidelity with which parents implemented behavioral plans at home was assessed via self-reports and permanent products (Sheridan, Swanger-Gagné, Welch, Kwon, \& Garbacz, 2009). Individual intervention plans developed for each student contained 3 to 12 criteria (e.g., provided sticker for meeting goal and reviewed and signed home-note). Fidelity checklists were developed for each behavioral intervention plan. The criteria of each intervention were listed on intervention implementation integrity checklists. Each of the criteria listed on the checklists were transferred onto self-report and permanent product record forms as appropriate (i.e., some intervention steps were not observable on permanent products; these were included on only the self-report forms).

Self-report record forms were completed by parents daily while the intervention was in place. Parents received self-report plan summary forms at intervention planning meetings and were asked to self-record completion of all steps of plan implementation on a daily basis. Each step was scored as "Yes" (step completed), "No" (step not completed), or "Not Applicable" (e.g., the child did not meet goal and failed to receive a reward). Intervention criteria notable on the permanent products (e.g., stickers received on chart and parent signature on daily home-school note) were transferred onto a specially developed record form and coded by research assistants. Because permanent products were structured differently across cases (i.e., some were completed on a daily basis, such as home-notes whereas others covered multiple days, such as weekly goal charts), there was variability in the number of permanent products possible across cases. An average of 13.26 permanent products were collected from parents across cases (median $=14$; range $=1$ to $26 ; S D=5.87$ ).

All permanent products collected were scored by two raters to assess interrater agreement of intervention implementation. Exact agreement across raters was $88 \%$. Interrater 
reliability for the permanent product measures was computed using intra-class correlation coefficients (ICC), interpreted as the percent of the variability in fidelity scores that are due to the differences across the cases that were rated, controlling for chance agreement. An ICC of .63 for home measures suggests that $63 \%$ of the variability in permanent product fidelity scores was due to the difference across the cases that were rated. Increased reliability was noted with the use of two raters, for which the ICC was estimated at .77.

\subsection{Research design and statistical analyses}

A randomized experimental design with repeated measures was applied in this study. Randomization of participants to condition occurred at the classroom level (i.e., upon enrollment in the study, teachers within schools were randomly assigned to treatment or control conditions). Analyses utilized multi-wave (pretest and posttest) data collected from 207 students including 113 students in the CBC group. We used a change-regression model (CRM; McArdle, 2009) by combining features of an auto-regression model (that utilizes ANCOVA to remove preexisting differences) and a change score model (that uses repeated measures ANOVA to examine change). CRM avoids errors that occur due to an uncontrolled grouping effect (Lord, 1967).

To address the first two research questions (i.e., evaluating parent and child outcomes), we fit a CRM using latent difference scores for each outcome. The CRM can be expressed as a difference model

$$
Y[2]_{n}=Y[1]_{n}+\Delta y_{n}
$$

by adding a CBC variable to a regression of a latent difference score

$$
\Delta \mathrm{y}_{n}=\mathrm{g}_{0}+\mathrm{g}_{1} C B C_{n}+\mathrm{g}_{2} Y[1]_{n}+d_{n}
$$

where $Y[1]_{n}$ is an outcome at pretest, and $Y[2]_{n}$ is an outcome at posttest, and $d_{n} \sim N\left(0, \sigma^{2} d\right)$. In the equation, $\Delta y_{n}$ represents an unobserved "true change" at the second occasion, which allows us to investigate the effect of $\mathrm{CBC}$ on true change in the outcome of interest (i.e., family involvement as assessed via the FIQ-E home-based involvement, school-based involvement, and home-school communication scores; parent competence in problem solving as assessed with the PCPS; and child behaviors of arguing, defiance, noncompliance, teasing, and tantrums as assessed on the PDR).

The CRM can be depicted as a path diagram as in figure 1. In figure $1, g_{0}$ is the average difference in outcome across time, $g_{1}$ is the change in the intercept in outcome across time for the CBC group, and $g_{2}$ is the slope coefficient for $Y[1]_{n}$ on the true change, $\Delta y_{n}$. The parameters of greatest interest to this research question are $\sigma_{1, \mathrm{CBC}}$ indicating the initial group difference in outcome and $g_{1}$ indicating the difference for the CBC group in the average true change in outcome. A statistically significant positive $g_{1}$ implies a positive effect of $\mathrm{CBC}$ on change in outcome (i.e., outcomes for participants in the $\mathrm{CBC}$ condition improve over time more than those in the control condition). 


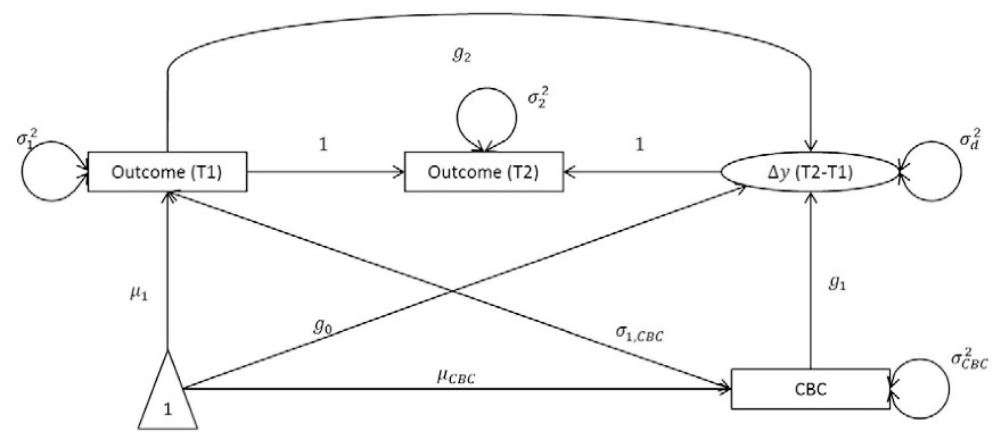

Figure 1. Path diagram for a change-regression model (CRM). Outcomes = Family Involvement Questionnaire (FIQ), Parent Competence in Problem Solving (PCPS), Parent Daily Report (PDR) at T1 (pretest); FIQ, PCPS, PDR at T2 (posttest); $g_{0}=$ intercept (average difference) of parent (or child) outcome for the control group; $g_{1}=$ change in the intercept (average difference) of parent (or child) outcome for the CBC group; $g_{2}=$ regression coefficient of a parent (or child) outcome at pretest on the difference of parent (or child) outcome; $\mu_{1}=$ mean of the parent (or child) outcome at pretest; $\mu_{\mathrm{CBC}}=$ mean of the $\mathrm{CBC}$ variable; $\sigma^{2}{ }_{1}=$ variance of the parent (or child) outcome at pretest; $\sigma^{2} \mathrm{CBC}=$ variance of the $\mathrm{CBC}$ variable; $\sigma_{1, \mathrm{CBC}}=$ covariance between the parent (or child) outcome at pretest and the CBC variable; $\sigma_{2}^{2}=$ residual variance of the parent (or child) outcome at posttest; $\sigma^{2} \mathrm{~d}=$ residual variance of the intercept (average difference) of the parent (or child) outcome; 1 = fixed parameters for the regression coefficients on the parent (or child) outcomes at posttest.

To address the third research question, moderator (or interaction) effects were investigated with the CRM expressed as a difference model

$$
Y[2]_{\mathrm{n}}=Y[1]_{n}+\Delta y_{n}
$$

by adding interaction terms on a regression of a latent difference score

$$
\begin{aligned}
\Delta y_{n}= & g_{0}+g_{1} C B C_{n}+g_{2} Y[1]_{n}+g_{3} \text { Childage }_{n}+g_{4} \text { Risk }_{n}+g_{5} \text { Disability }_{n}+ \\
& g_{6} C B C_{n} \cdot \text { Childage }_{n}+g_{7} C B C_{n} \cdot \text { Risk }_{n}+g_{8} C B C_{n} \cdot \text { Disability }_{n}+d_{n}
\end{aligned}
$$

Similarly, a statistically significant positive $g_{i}$, for $i=6,7$, and 8 , implies a significant moderator effect of $\mathrm{CBC}$ for each covariate. The model with the interaction term is a "wellformulated" model focusing solely on the examination of the interaction term but not interpreting the lower order terms as main effects, CBC and Risk in the model, for example (Morrell, Pearson, \& Brant, 1997; Peixoto, 1987). In other words, when interaction effects are present, the interpretation of main effects in the well-formulated model could be incomplete or misleading.

Based on previous research (Sheridan, Eagle, \& Doll, 2006; Sheridan et al., 2001), the following moderators were investigated to determine the degree to which they influenced CBC's effects: child age, presence of a disability, and cumulative risk experienced by the 
family. Using the deviance information criterion for model comparison, posterior predictive checks for model fit (Gelman, Carlin, Stern, \& Rubin, 2004; Spiegelhalter, Best, Carlin, \& van der Linde, 2002) and the significance of child or family variables in model comparison, family risk was found to be statistically significant for several parent and child outcomes. The resulting CRM, including the family risk variable, can be written as

$$
Y[2]_{n}=Y[1]_{n}+\Delta y_{n}
$$

When the interaction between $\mathrm{CBC}$ and family risk is added to the regression equation of a latent difference score, the model can be expressed

$$
\Delta y_{n}=g_{0}+g_{1} C B C_{n}+g_{2} Y[1]_{n}+g_{3} R_{i s k_{n}}+g_{4} C B C_{n} \cdot R i s k_{n}+d_{n}
$$

where the parameter of interest $\left(g_{4}\right)$ represents the moderated effect of CBC on parent and child outcomes. Because the CRMs include a latent difference score, all parameters in the CRMs were estimated using the statistical package for structural equation model, Mplus 7.0 (Muthén \& Muthén, 2012).

\section{Results}

We first provide information regarding fidelity of $\mathrm{CBC}$ procedures and behavioral intervention implementation. Second, we report $\mathrm{CBC}^{\prime}$ s effects on parent and child behaviors at home. Finally, we present results of moderation analyses.

\subsection{Fidelity of $C B C$ and behavioral intervention implementation}

In all, 211 CBC interviews were digitally audio-recorded. Close to half $(45 \%)$ of all interviews $(n=94)$ were coded by trained coders to assess fidelity to the model. Consultants met $99 \%$ of the objectives during Needs Identification/Needs Analysis, $98 \%$ of the objectives during Plan Development and Implementation, and $98 \%$ of the objectives during the Plan Evaluation interviews. Close to $20 \%$ of coded interviews $(n=18)$ were rated by two observers, with $96 \%$ overall agreement.

Behavioral plan implementation fidelity was assessed via parent self-report and permanent product record forms. Self-reports and permanent products were submitted by $50 \%$ and $68 \%$ of parents, respectively. Across methods, moderate to high levels of treatment plan implementation were found. Specifically, parents self-reported adhering to an average of $82 \%$ of the home intervention steps. Review of permanent products revealed that on average, $89 \%$ of plan objectives were met.

\subsection{Effect of $C B C$ on parents and children}

The primary purpose of the present study was to investigate the effects of $\mathrm{CBC}$ on parent and child outcomes. In particular, the effects of $\mathrm{CBC}$ on family involvement and parent competence in problem solving were evaluated, as well as child behaviors at home (i.e., arguing, defiance, noncompliance, teasing, and tantrums). Descriptive statistics for all parent and child measures for both experimental groups across assessment occasions are in 
displayed in table 3. Results of the effects of CBC on parent and child outcomes are presented in table 4 with unstandardized estimates of $g_{1}$ and their standard errors. Figures 2 and 3 represent pretest and posttest results across conditions for variables for which statistically significant effects for parents and children were found, respectively. Results will be presented as they pertain to each of the primary research questions.

Table 3. Means (standard deviations) of the study variables across groups and conditions.

\begin{tabular}{|c|c|c|c|c|}
\hline & \multicolumn{2}{|c|}{ СВC } & \multicolumn{2}{|c|}{ Control } \\
\hline & Pretest & Posttest & Pretest & Posttest \\
\hline \multicolumn{5}{|l|}{ Parent outcomes } \\
\hline \multirow[t]{2}{*}{ Parent competence in problem-solving scale } & 4.58 & 4.97 & 4.49 & 4.64 \\
\hline & $(0.68)$ & $(0.62)$ & $(0.81)$ & $(0.71)$ \\
\hline \multicolumn{5}{|l|}{ Family involvement questionnaire } \\
\hline \multirow[t]{2}{*}{ Home-school communication } & 2.57 & 2.91 & 2.70 & 2.77 \\
\hline & $(0.78)$ & $(0.70)$ & $(0.57)$ & $(0.60)$ \\
\hline \multirow[t]{2}{*}{ Home-based involvement } & 3.04 & 3.04 & 3.14 & 3.11 \\
\hline & $(0.47)$ & $(0.53)$ & $(0.42)$ & $(0.46)$ \\
\hline \multirow[t]{2}{*}{ School-based involvement } & 1.81 & 1.84 & 1.90 & 1.93 \\
\hline & $(0.56)$ & $(0.52)$ & $(0.46)$ & $(0.51)$ \\
\hline \multirow[t]{2}{*}{ Family involvement: total score } & 2.52 & 2.64 & 2.63 & 2.65 \\
\hline & $(0.47)$ & $(0.50)$ & $(0.35)$ & $(0.41)$ \\
\hline \multicolumn{5}{|l|}{ Child outcomes } \\
\hline \multicolumn{5}{|l|}{ Parent daily report } \\
\hline \multirow{2}{*}{ Total problems } & 6.18 & 4.61 & 7.94 & 6.56 \\
\hline & $(3.69)$ & $(3.19)$ & $(4.81)$ & $(5.37)$ \\
\hline \multirow[t]{2}{*}{ Arguing } & 0.59 & 0.39 & 0.55 & 0.47 \\
\hline & $(0.36)$ & $(0.35)$ & $(0.37)$ & $(0.34)$ \\
\hline \multirow[t]{2}{*}{ Defiance } & 0.30 & 0.15 & 0.36 & 0.30 \\
\hline & $(0.36)$ & $(0.25)$ & $(0.36)$ & $(0.33)$ \\
\hline \multirow[t]{2}{*}{ Noncompliance } & 0.51 & 0.31 & 0.40 & 0.38 \\
\hline & $(0.41)$ & $(0.34)$ & $(0.36)$ & $(0.37)$ \\
\hline \multirow[t]{2}{*}{ Teasing } & 0.21 & 0.12 & 0.18 & 0.14 \\
\hline & $(0.34)$ & $(0.21)$ & $(0.29)$ & $(0.26)$ \\
\hline \multirow[t]{2}{*}{ Tantrums } & 0.18 & 0.10 & 0.20 & 0.19 \\
\hline & $(0.30)$ & $(0.17)$ & $(0.30)$ & $(0.28)$ \\
\hline
\end{tabular}

Note: Parent Competence in Problem-solving scores are mean item ratings across participants. Possible range $=1$ to 6 , with high scores reflecting greater competence in problem solving. Family Involvement Questionnaire scores are mean item ratings across participants. Possible range $=1$ to 4 , with high scores indicating greater levels of involvement. Parent Daily Report total problems scores reflect average count of problem behaviors across participants. 
Table 4. Effects of CBC on parent and child outcomes.

\begin{tabular}{lccc}
\hline & \multicolumn{1}{c}{$g_{1}$} & & \\
& Unstandardized estimate (S.E.) & $p$ & Effect size \\
\hline $\begin{array}{l}\text { Parent outcomes } \\
\text { Parent competence in problem-solving scale }\end{array}$ & & & \\
Family involvement questionnaire & & & \\
Home-school communication & & $<.366(0.090)$ & 0.697 \\
Home-based involvement & $0.181(0.024)$ & \\
School-based involvement & $0.044(0.050)$ & $.025^{*}$ & 0.519 \\
Family involvement: total score & $-0.030(0.047)$ & .382 & 0.400 \\
Child outcomes & $0.064(0.045)$ & .518 & -0.306 \\
Parent daily report & & .159 & 0.703 \\
Total problems & & & \\
Arguing & & & \\
Defiance & $-0.572(0.437)$ & .191 & -0.072 \\
Noncompliance & $-0.107(0.048)$ & $.025^{*}$ & -0.899 \\
Teasing & $-0.119(0.038)$ & $.002^{* *}$ & -1.337 \\
Tantrums & $-0.129(0.048)$ & $.007^{* *}$ & -1.049 \\
\hline
\end{tabular}

Note: ${ }^{*} p<.05 ;{ }^{* *} p<.01 ;{ }^{* * *} p<.001$
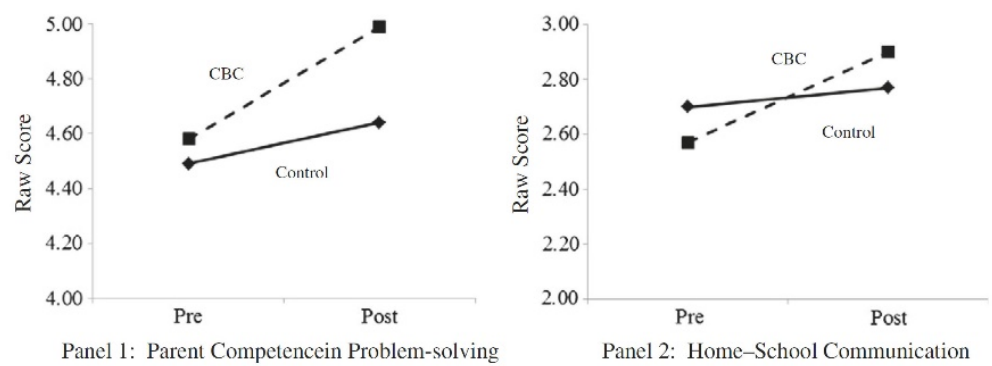

Figure 2. Parent ratings of competence in problem solving (Panel 1) and home-school communication (Panel 2) at pretest and posttest for participants in conjoint behavioral consultation $(\mathrm{CBC})$ and control conditions. 

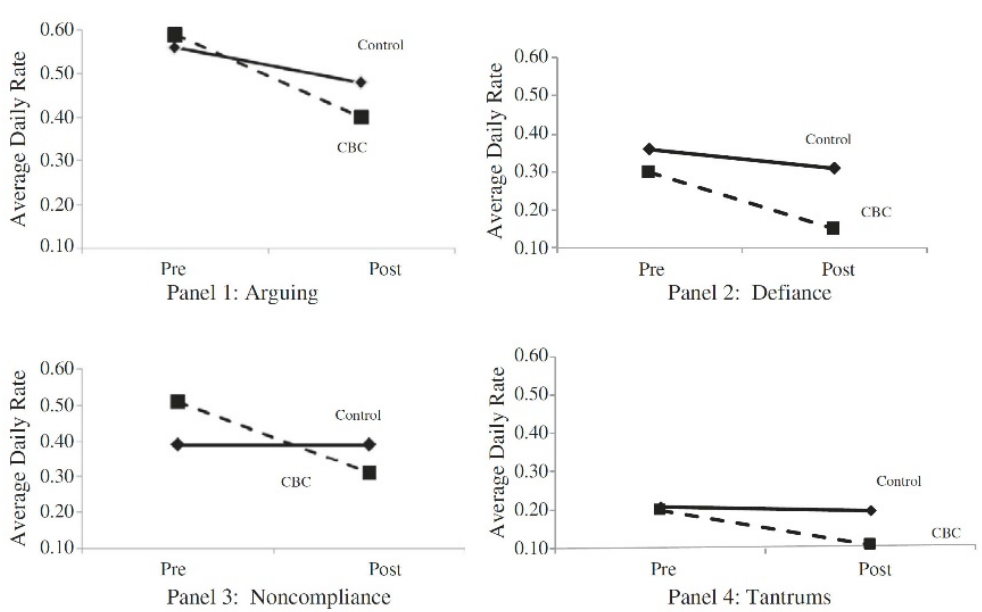

Figure 3. Frequency of child arguing (Panel 1), defiance (Panel 2), noncompliance (Panel 3), and tantrums (Panel 4) at home for participants in CBC and control conditions at pretest and posttest.

\subsection{Research Question 1: What is the effect of CBC on family involvement and parent competence in problem solving?}

No differences were found between parents of children in the treatment and control groups for family involvement (overall, or for home-based involvement, school-based involvement, or home-school communication) at pretest ( $p^{\prime}$ s for $\left.\sigma_{1, \mathrm{CBC}} \mathrm{s}>.05\right)$. As evident in table 4 , of the three factors on the FIQ, a statistically significant effect (in favor of the treatment group) was noted for home-school communication $\left(g_{1}=0.181, p=.025\right)$. The obtained effect size $(d=0.519)$, interpreted as a standardized metric under the standard normal curve, indicates that the CBC group achieved greater gains than approximately $70 \%$ of control group participants.

There was no difference between parents of children in the treatment and control groups for parent competence in problem solving at pretest ( $p$ for $\sigma_{1, \mathrm{CBC}}>.05$ ). Compared to the control group, parents of children in the $\mathrm{CBC}$ group reported a significantly greater increase in competence in problem solving $\left(g_{1}=0.366, p<.001\right)$. The obtained effect size $(d$ $=0.697$ ) suggests that the average parent participant in the CBC group scored higher in parental competence in problem solving at posttest than approximately $76 \%$ of control group participants.

\subsection{Research Question 2: What is the effect of CBC on disruptive child behaviors at home?}

$\mathrm{CBC}$ was found to have a statistically significant effect on child behaviors in the home setting. As noted in table 4, children in the CBC group showed significantly greater decreases in the frequency of arguing $\left(g_{1}=-0.107, p=.025, d=-0.899\right)$, defiance $\left(g_{1}=-0.119\right.$, $p=.002, d=-1.337)$, noncompliance $\left(g_{1}=-0.129, p=.007, d=-1.049\right)$, and tantrums $\left(g_{1}=\right.$ $-0.083, p=.003, d=-1.537$ ) behaviors compared to children in the control group. Children in the $\mathrm{CBC}$ group also showed a greater decrease in the frequency of teasing and total problem behaviors compared to children in the control group, but these differences were 
not statistically significant ( $p^{\prime}$ s $=.184$ and .191 , respectively). Obtained effect sizes for arguing, defiance, noncompliance, and tantrums suggest that on average, children in the CBC condition performed better than between $82 \%$ and $94 \%$ of children in the control group.

\subsection{Research Question 3: Are the effects of CBC on parent and child outcomes moderated} by child or family variables?

Moderator effects of family risk on the impact of $\mathrm{CBC}$ on parent and child outcomes based on the CRM are presented in table 5. Equation (4) reflects the trajectories of change in outcome as it is moderated by family risk for the CBC treatment and control groups separately. Figure 4 visually depicts the moderating effect of family risk on parent competence in problem solving (Panel 1) and total child problem behaviors (Panel 2) for the treatment and control groups.

\begin{tabular}{|c|c|c|c|c|c|c|}
\hline & \multirow[b]{2}{*}{$\sigma_{1, \mathrm{CBC}}$} & \multicolumn{5}{|c|}{ Unstandardized estimates } \\
\hline & & $g_{0}$ & $g_{1}$ & $g^{2}$ & $g_{3}$ & $\begin{array}{c}g_{4} \\
(p ; d)\end{array}$ \\
\hline \multicolumn{7}{|l|}{ Parent outcomes } \\
\hline $\begin{array}{l}\text { Parent competence in problem- } \\
\text { solving Scale }\end{array}$ & -.019 & 2.780 & 0.189 & -0.574 & -0.129 & $\begin{array}{c}0.275 \\
\left(.020^{*} ; 0.522\right)\end{array}$ \\
\hline \multicolumn{7}{|l|}{ Family involvement questionnaire } \\
\hline Home-school communication & -.017 & 1.255 & 0.141 & -0.443 & 0.037 & $\begin{array}{c}0.057 \\
(.584 ; 0.165)\end{array}$ \\
\hline Home-based involvement & -.016 & 0.859 & -0.015 & -0.267 & -0.052 & $\begin{array}{c}0.094 \\
(.160 ; 0.832)\end{array}$ \\
\hline School-based involvement & -.016 & 0.478 & -0.044 & -0.216 & -0.009 & $\begin{array}{c}0.024 \\
(.720 ; 0.240)\end{array}$ \\
\hline Family involvement: total score & -.016 & 0.675 & 0.026 & -0.240 & -0.002 & $\begin{array}{c}0.056 \\
(.354 ; 0.602)\end{array}$ \\
\hline \multicolumn{7}{|l|}{ Child outcomes } \\
\hline Total problems & -.297 & -0.797 & 0.456 & -0.189 & 1.058 & $\begin{array}{c}-1.246 \\
\left(.008^{* *} ;-0.161\right)\end{array}$ \\
\hline Arguing & .009 & 0.155 & -0.059 & -0.499 & 0.077 & $\begin{array}{c}-0.081 \\
(.208 ;-0.669)\end{array}$ \\
\hline Defiance & -.018 & 0.108 & -0.081 & -0.526 & 0.044 & $\begin{array}{c}-0.061 \\
(.248 ;-0.726)\end{array}$ \\
\hline Noncompliance & .027 & 0.125 & -0.067 & -0.509 & 0.108 & $\begin{array}{c}-0.107 \\
(.096 ;-0.884)\end{array}$ \\
\hline Teasing & .009 & 0.039 & 0.015 & -0.559 & 0.045 & $\begin{array}{c}-0.082 \\
\left(.044^{*} ;-1.242\right) \\
-0.089\end{array}$ \\
\hline Tantrums & -.006 & 0.070 & -0.029 & -0.531 & 0.056 & $\left(.012^{*} ;-1.679\right)$ \\
\hline
\end{tabular}

Note: $g_{0}=$ average difference in outcome across time; $g_{1}=$ main effect of CBC; $g_{2}=$ regression coefficient of $Y[1]$ to $\Delta y ; g_{3}=$ main effect of risk; $g_{4}=$ moderator (interaction) effect of $\mathrm{CBC}$ with risk. $p$ values and effect sizes are reported for the interaction effect of $\mathrm{CBC}$ with risk $\left(g_{4}\right)$ variables for which significant effects are present. ${ }^{*} p<.05 ;{ }^{* *} p<.01 ;{ }^{* * *} p<.001$ 

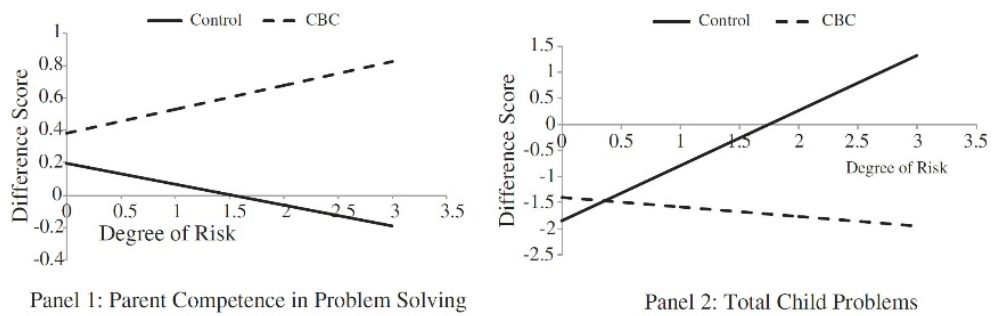

Figure 4. Latent difference scores in parent competence in problem solving (Panel 1) and total child problem behaviors (Panel 2), as moderated by family risk, for CBC and control groups.

\subsubsection{Moderators of parent outcomes}

As depicted in table 5, degree of family risk was found to be a statistically significant moderator of the effects of CBC on parent competence in problem solving $\left(g_{4}=0.275[p=.020\right.$, $d=0.522]$ ). That is, parents of children in the CBC group showed a greater increase in parent competence in problem solving compared to the control group. As represented in figure 4 (Panel 1), the increase of the latent difference score in parent competence (along the $y$ axis)was found to be significantly greater for parents of children in the CBC group with higher risk scores (denoted along the $x$ axis). The degree of family risk was not found to moderate the effects of $\mathrm{CBC}$ on any other parent outcomes.

\subsubsection{Moderators of child outcomes}

As shown in table 5, degree of family risk was also found to be a significant moderator of the effects of CBC on total behavior problems $\left(g_{4}=-1.246[p=.008, d=-0.161]\right)$, teasing $\left(g_{4}\right.$ $=-0.082[p=.044, d=-1.242])$, and tantrums $\left(g_{4}=-0.089[p=.012, d=-1.679]\right)$. That is, the frequency of these specific disruptive behaviors showed a significantly greater decrease for children in the $C B C$ group who experienced greater levels of cumulative family risk compared to both $\mathrm{CBC}$ children with fewer risk variables, and children in the control group. Degree of family risk was not found to moderate the effects of $\mathrm{CBC}$ on the frequencies of arguing, defiance, or noncompliance. Figure 4 (Panel 2) shows that as family risk increases (along the $x$ axis), the latent difference score in child problem behaviors (along the $y$ axis) increase for control group participants and decrease for $\mathrm{CBC}$ participants.

\section{Discussion}

The present study investigated the effects of $\mathrm{CBC}$ on family variables (i.e., family involvement and parent competence in problem solving) that are commonly associated with important outcomes among school-aged children. In addition, although decades of efficacy research attests to the benefits of CBC for academic (Weiner et al., 1998), behavioral (Sheridan et al., 2012), and social behaviors (Owens et al., 2008) in the school setting, this study is the first to date to report clear child behavioral outcomes within the home environment. The use of a large sample of students who demonstrated disruptive behaviors randomly assigned to active $\mathrm{CBC}$ or control group conditions represented a unique methodological 
approach because the majority of $\mathrm{CBC}$ outcome studies to date utilized single case designs. Family and child variables that moderated CBC's treatment effects were explored.

\subsection{Main findings and implications for practice}

This study is the first to report the effects of $\mathrm{CBC}$ on salient parent behaviors. Findings are highly encouraging and suggest that CBC effectively increased home-school communication and parent competence in problem solving, relative to a control condition. That is, relative to a control group of parents of children with behavioral concerns, those participating in the collaborative CBC process experienced gains in self-reported communication with their children's teachers.

Similarly, parents reported significantly greater gains in their own competence in problem-solving, such as setting goals for their child, identifying and implementing specific strategies that can be changed to help their child's behavior, and gathering information to assess their child's progress. Such behaviors that promote the active participation of families are instrumental in children's success (Hoagwood, 2005). Whereas the benefits of parent-teacher communication and partnerships have been touted repeatedly (Allen, 2007), heretofore, there have been no randomized controlled trials investigating interventions to promote these practices. CBC is among the first family-school partnership model validated through a rigorous efficacy trial (Sheridan et al., 2012).

Alternatively, although gains in home- and school-based involvement as a function of collaborative processes and $\mathrm{CBC}$ were expected, there were no significant differences between groups on these other forms of involvement. Items tapping family involvement on the FIQ-E (Manz et al., 2004) were broad and inclusive (e.g., "I bring home learning materials for my child" for home-based involvement and "I go on class trips with my child" for school-based involvement). Although these are desirable activities, items on the FIQ-E may have been insensitive for capturing the effects targeted in this $\mathrm{CBC}$ intervention.

In addition to significant effects for parent problem-solving and communication behaviors, children whose parents and teachers participated in CBC demonstrated significantly greater decreases in several specific behaviors as measured through parent daily reports (PDRs), relative to children receiving "business as usual" (e.g., special education, outpatient therapy, or family counseling). These behaviors (i.e., arguing, defiance, noncompliance, and tantrums) were frequent targets in $\mathrm{CBC}$ and were positively affected by the constructive, collaborative CBC process. It is noteworthy that at the general group level, significant differences in total behavior problems on the PDR were not observed for children receiving $\mathrm{CBC}$ services relative to their non-CBC counterparts. Although somewhat surprising, it is likely that specificity in the $\mathrm{CBC}$ process (i.e., comprising clearly identifying, defining, and treating target behaviors rather than global concerns or indicators) translated into distinctive behavioral gains in home environments. Parents were aided in developing and implementing procedures that were specific to targeted behavioral priorities, and results mirrored this level of precision. To date there are no large-scale research studies reporting the results of $\mathrm{CBC}$ on behaviors directly observed within school settings; similar research is needed in authentic classroom settings to confirm the utility of behavioral specification for addressing target behaviors in the context of CBC interventions. 


\subsection{CBC and family risk}

CBC research to date has not revealed conditions under which effects are most pronounced, or family or child variables that amplify the benefits of the model. In the current era of evidence-based practice and service delivery, understanding the conditions under which intervention effects can be augmented holds a great deal of treatment utility. Likewise, there is mounting emphasis on the need to identify and implement effective treatments using approaches that are idiosyncratic and efficient (Forman et al., 2013). Thus, uncovering tailor-made interventions that appear to hold promise for specific individuals in specified contexts and can effectively bridge the science-to-practice gap is of increased relevance. In the current study, the accumulation of family risk (i.e., low parental education, low income status, fewer than two adults in the household) moderated the effects of CBC on both parent and child outcomes. That is, greater treatment gains were observed in situations of greater degrees of family risk; as the level of family risk increased, so did the effects of $C B C$. This suggests that $C B C$ was most effective for families who experienced the greatest degree of demographic disadvantage.

Our findings uncovering the interaction between $\mathrm{CBC}$ and family disadvantage (i.e., indicating that the effects of $\mathrm{CBC}$ are amplified for families at demographic risk) are consistent with others who have reported that children and families with significant levels of disadvantage or risk may be particularly responsive to family-centered interventions (Stormshak, Connell, \& Dishion, 2009). Children of women identified as having low psychological resources (i.e., limited intellectual functioning, mental health, and sense of personal control) were found to respond favorably to nurse-delivered home visits at six and 21 months of age (Olds et al., 2002). Greater parental engagement in services has been noted for parents who were considered at risk for parenting difficulties (Daro, McCurdy, Falconnier, \& Stojanovic, 2003; McCurdy et al., 2006) than their counterparts. In the present study, CBC employed an individualized, responsive family centered approach to promote engagement similar to that used in other home visitation studies. The fact that families who experienced the greatest degrees of disadvantage made the greatest gains in parent competence in educational problem solving is very promising. Too often, these families are marginalized from the educational system, and challenges realizing meaningful and relevant roles result. More research is needed to understand the actual mechanisms responsible for establishing significant positive effects of these relationship-based programs in home settings of families at risk.

Degree of family risk was also a significant moderator of the effects of $\mathrm{CBC}$ on child teasing, tantrums, and total problem behaviors. A significantly greater decrease in problem behaviors was found for children in families with increasing levels of cumulative risk. That is, as with parental levels of competence in problem solving, the behavioral outcomes of CBC in home settings were amplified for students in families with increasing levels of disadvantage. It is not clear why these behaviors (i.e., tantrums and teasing) were the only ones moderated by family risk; future research may explore the unique role of other variables that may influence $C B C^{\prime}$ s effects for other targeted disruptive child behaviors. 


\subsection{Limitations and future research}

Exploring the mechanisms by which interventions work to produce desired effects is becoming increasingly important in applied research. Uncovering significant mediating variables is meaningful in enhancing an empirical understanding of critical treatment elements and refining theories of behavioral change, thereby further explicating significant processes for replication, dissemination, and translation. Unfortunately, our measurement schedule (i.e., requiring collection of repeated measures of child outcomes including measurement occasions that preceded or were simultaneous to assessment of parent outcomes) precluded our ability to test whether parent problem-solving or communication with teachers were responsible for significant child effects. Other unmeasured processes (e.g., positive parenting practices, parent-child interactions, continuity between home and school) may also have been instrumental in facilitating CBC's effects on students with or at risk for behavioral problems. Future research dedicated to uncovering operative pathways of CBC's effects on parents and students is sorely needed.

The results of this study are highly encouraging; however, some limitations warrant that caution be exercised when interpreting the results. First, the sample in this study was derived from a set of families of students nominated by their teachers as having externalizing behavioral concerns, and who agreed to participate in the collaborative home-school process. They were therefore a select sample and not necessarily representative of the scope of families of students with or at risk of developing behavioral problems. Further research may investigate processes for engaging families who did not consent to participate and understanding methods for creating connections and increasing access to CBC services. Second, the measures used to assess family involvement and parent competence in problem solving were based on self-reports, and parents' responses were not corroborated by direct, objective measures. Objective methods for detailing parental practices (i.e., communication, engagement, and collaboration) are necessary to further elucidate the effect of CBC on these outcomes as well as their role in educational effects. Relatedly, parents were the primary providers of child outcome data and were not blind to their assignment to treatment or control condition; these outcomes require objective validation. Fourth, child outcomes were limited to disruptive behaviors as assessed on the Parent Daily Report (Chamberlain \& Reid, 1987). Other behaviors may have been positively affected by CBC, such as homework and social skills; however, they went unmeasured. Finally, fidelity of home-based intervention implementation was measured in largely indirect ways. Despite careful home-school plan development and manualization of procedures, little is actually known about specific strategies used by parents.

\subsection{Conclusions}

In conclusion, results from this study demonstrate evidence of promise for $\mathrm{CBC}$ as an intervention for children at behavioral risk for deleterious outcomes. It meets the critical need of promoting collaborative partnerships for parents of children who are exhibiting behavioral and social-emotional challenges with resultant changes in parent competence in problem-solving, home-school communication, and child outcomes in the home setting. Identifying characteristics of children and families that position them to benefit from the 
intervention has been unexplored in previous research. The determination of $\mathrm{CBC}$ as particularly effective under conditions of increasing risk suggests significant potential to advance research-based services for children and families who are most vulnerable.

Acknowledgments - This study was supported by a federal grant awarded to the first author by the U.S. Department of Education Institute of Education Sciences (Grant \#R305F050284). The opinions expressed herein are those of the authors and are not considered reflective of the funding agency. The authors are indebted to many who contributed in the conceptualization and implementation of this study, additional members of the research team (Michelle Swanger-Gagné, Lynae Frerichs, and Shannon Dowd-Eagle), field-based partners (Sue Braun and Kathy Johnson), and the many teachers, parents, and students whose participation and partnership made this study a reality.

\section{Notes}

1. The researcher-developed scale used for screening purposes is available from the first author.

2. Because demographic information from parents was collected following their consent to participate, an exploration of potential differences among participating and nonparticipating families is not possible. Available screening data indicate pretreatment severity ratings (made by teachers) for students participating in the study (i.e., for whom parental consent was obtained) averaged 6.7 (on a scale of 1 [not at all] to 9 [very severe]). For nonparticipants (i.e., students for whom parental consent was not provided), severity ratings averaged 6.41.

3. Given the conjoint nature of $\mathrm{CBC}$, complementary interventions were also delivered at school. At school, $96 \%, 58 \%, 42 \%$, and $13 \%$ of intervention packages consisted of positive consequences, antecedent control strategies, skill building, and reductive techniques, respectively. Information on the fidelity with which teachers implemented plan tactics in the classroom is available in Sheridan, Swanger-Gagné et al. (2009) and Sheridan et al. (2012).

\section{References}

Ackerman, B., Kogos, J., Youngstrom, E., Schoff, K., \& Izard, C. (1999). Family instability and the problem behaviors of children from economically disadvantaged families. Developmental Psychology, 35, 258-268.

Allen, J. (2007). Creating welcoming schools: A practical guide to home-school partnerships with diverse families. New York: Teachers College Press and International Reading Association.

Appleyard, K., Egeland, B., van Dulmen, M. H. M., \& Sroufe, L. A. (2005). When more is not better: The role of cumulative risk in child behavior outcomes. Journal of Child Psychology and Psychiatry, 46, 235-245.

Barry, L. M., \& Santarelli, G. E. (2000). Making it work at school and home: A need based collaborative, across settings, behavioral intervention. The California School Psychologist, 5, 43-51.

Brauner, C. B., \& Stephens, C. B. (2006). Estimating the prevalence of early childhood serious emotional/behavioral disorders: Challenges and recommendations. Public Health Reports, 121, 303310.

Bronfenbrenner, U. (1979). The ecology of human development: Experimental by nature and design. Cambridge, MA: Harvard University Press.

Bronfenbrenner, U. (1992). Ecological systems theory. In R. Vasta (Ed.), Six theories of child development: Revised formulations and current issues (pp. 187-248). Philadelphia, PA: Jessica Kingsley. 
Burchinal, M. R., Peisner-Feinberg, E., Pianta, R., \& Howes, C. (2002). Development of academic skills from preschool through second grade: Family and classroom predictors of developmental trajectories. Journal of School Psychology, 40, 415-436.

Campbell, S. B. (1991). Longitudinal studies of active and aggressive preschoolers: Individual differences in early behavior and outcome. In D. Cicchetti, \& S. L. Toth (Eds.), Rochester Symposium on Developmental Psychopathology. Internalizing and externalizing expressions of dysfunction, 2. (pp. 5790). Hillsdale, NJ: Erlbaum.

Chamberlain, P., \& Reid, J. B. (1987). Parent observation and report of child symptoms. Behavioral Assessment, 9, 97-109.

Colton, D., \& Sheridan, S.M. (1998). Conjoint behavioral consultation and social skills training: Enhancing the play behavior of boys with attention deficit-hyperactivity disorder. Journal of Educational and Psychological Consultation, 9, 3-28.

Connell, A. M., Dishion, T. J., Yasui, M., \& Kavanagh, K. (2007). An adaptive approach to family intervention: Linking engagement in family-centered intervention to reductions in adolescent problem behavior. Journal of Consulting and Clinical Psychology, 75, 568-579, http://dx.doi.org/10 $.1037 / 0022-006 X .75 .4 .568$.

Cox, D. D. (2005). Evidence-based interventions using home-school collaboration. School Psychology Quarterly, 20, 473-497.

Curtis, W. J., \& Singh, N. N. (1996). Family involvement and empowerment in mental health service provision for children with emotional and behavioral disorders. Journal of Child \& Family Studies, 5, 503-517.

Daro, D., McCurdy, K., Falconnier, L., \& Stojanovic, D. (2003). Sustaining new parents in home visitation services: Key participant and program factors. Child Abuse \& Neglect, 27, 1101-1125, http://dx.doi.org/10.1016/j.chiabu.2003.09.007.

Downer, J. T., \& Myers, S. S. (2010). Application of a developmental/ecological model to familyschool partnerships. In S. L. Christenson, \& A. L. Reschly (Eds.), Handbook on school-family partnerships (pp. 3-29). New York, NY: Routledge.

Emond, A., Ormel, J., Veenstra, R., \& Oldehinkel, A. J. (2007). Preschool behavioral and socialcognitive problems as predictors of (pre)adolescent disruptive behavior. Child Psychiatry and Human Development, 38, 221-236.

Forman, S. G., Shapiro, E. S., Codding, R. S., Gonzales, J. E., Reddy, L. A., \& Rosenfield, S. A. (2013). Implementation science and school psychology. School Psychology Quarterly, 28, 77-100, http://dx .doi.org/10.1037/spq0000019.

Garbacz, S. A., \& Sheridan, S. M. (2011). A multidimensional examination of New Zealand family involvement in education. School Psychology International, 32, 600-615.

Gelman, A., Carlin, J. B., Stern, H. S., \& Rubin, D. B. (2004). Bayesian data analysis (2nd ed.) Boca Raton, FL: Chapman \& Hall.

Gibbons, R. D., Hedeker, D. R., \& Davis, J. M. (1993). Estimation of effect sizes from a series of experiments involving paired comparisons. Journal of Educational Statistics, 18, 271-279.

Guli, L. A. (2005). Evidence-based parent consultation with school-related outcomes. School Psychology Quarterly, 20, 455-472.

Hembree-Kigin, T. L., \& McNeil, C. B. (1995). Parent-child interaction therapy. New York, NY: Plenum Press.

Hoagwood, K. E. (2005). Family-based services in children's mental health: A research review and synthesis. Journal of Child Psychology and Psychiatry, 46, 690-713. 
Jenson, W. R., Rhode, G., \& Neville, M. H. (2010). The tough kid parent book: Practical solutions to tough childhood problems (2nd ed.)Eugene, OR: Pacific Northwest Publishing.

Jenson, W. R., Rhode, G., \& Reavis, K. H. (2009). The tough kid tool box (2nd ed.) Eugene, OR: Pacific Northwest Publishing.

Kazdin, A. E. (2005). Parent management training: Treatment for oppositional, aggressive, and antisocial behavior in children and adolescents. New York, NY: Oxford University Press.

Koren, P. E., Paulson, R. I., Kinney, R. F., Yatchmonoff, D. K., Gordon, L. J., \& DeChillo, N. (1997). Service coordination in children's mental health: An empirical study from the caregiver's perspective. Journal of Emotional and Behavioral Disorders, 5, 162-172.

Kratochwill, T. R., Elliott, S. N., Loitz, P. A., Sladeczek, I., \& Carlson, J. S. (2003). Conjoint consultation using self-administered manual and videotape parent-teacher training: Effects on children's behavioral difficulties. School Psychology Quarterly, 18, 269-302.

Kratochwill, T. R., \& Stoiber, K. C. (2002). Evidence-based interventions in school psychology: Conceptual foundations of the Procedural and Coding Manual of Division 16 and the Society for the Study of School Psychology Task Force. School Psychology Quarterly, 17, 341-389.

Landis, J. R., \& Koch, G. G. (1977). The measurement of observer agreement for categorical data. Biometrics, 33, 159-174.

Lasecki, K., Olympia, D., Clark, E., Jenson, W., \& Heathfield, L. T. (2008). Using behavioral interventions to assist children with type 1 diabetes manage blood glucose levels. School Psychology Quarterly, 23, 389-406.

Lines, C., Miller, G., \& Arthur-Stanley, A. (2011). The power of family-school partnering (FSP): A practical guide for school mental health professionals and educators. New York, NY: Routledge.

Loeber, R. (1991). Antisocial behavior: More enduring than changeable? Journal of the American Academy of Child and Adolescent Psychiatry, 30, 393-397.

Lord, F. M. (1967). A paradox in the interpretation of group comparisons. Psychological Bulletin, 68, 304-305.

Magnuson, K., \& Votruba-Drzal, E. (2009). Enduring influences of childhood poverty. Focus, 26(2), 32-37.

Manz, P. H., Fantuzzo, J. W., \& Power, T. J. (2004). Multidimensional assessment of family involvement among urban elementary students. Journal of School Psychology, 42, 461-475.

McArdle, J. J. (2009). Latent variable modeling of differences and changes with longitudinal data. Annual Review of Psychology, 60, 577-605.

McCain, A. P., \& Kelley, M. L. (1994). Improving classroom performance in underachieving preadolescents: The addictive effects of response cost to a school-home note system. Child \& Family Behavior Therapy, 16(2), 27-41.

McCurdy, K., Daro, D., Anisfeld, E., Katzev, A., Keim, A., LeCroy, C., et al. (2006). Understanding maternal intentions to engage in home visiting programs. Children and Youth Services Review, 28, 1195-1212, http://dx.doi.org/10.1016/j.childyouth.2005.11.010.

McDonald, L., Moberg, D. P., Brown, R., Rodriguez-Espiricueta, I., Flores, N. I., Burke, M. P., et al. (2006). After-school multifamily groups: A randomized controlled trial involving low-income, urban, Latino children. Children \& Schools, 28, 25-34.

McKay, M. M., \& Bannon, W. M., Jr. (2004). Engaging families in child mental health services. Child $\mathcal{E}$ Adolescent Psychiatric Clinics of North America, 13, 905-921.

McLeod, J. D., \& Shanahan, M. J. (1996). Trajectories of poverty and children's mental health. Journal of Health and Social Behavior, 37, 207-220. 
McMahon, R. J., \& Forehand, R. (2003). Helping the noncompliant child: A clinician's guide to effective parent training (2nd ed.) New York, NY: Guilford Press.

Moore, L. A., Waguespack, A. M., Wickstrom, K. F., Witt, J. C., \& Gaydon, G. R. (1994). Mystery motivator: An effective and time efficient intervention. School Psychology Review, 23, 106-117.

Morrell, C. H., Pearson, J. D., \& Brant, L. J. (1997). Linear transformations of linear mixed-effects models. The American Statistician, 51, 338-343.

Morris, S. B., \& DeShon, R. P. (2002). Combining effect size estimates in meta-analysis with repeated measures and independent-groups design. Psychological Methods, 7, 105-125.

Mortier, K., Hunt, P., Desimpel, L., \& Van Hove, G. (2009). With parents at the table: Creating supports for children with disabilities in general education classrooms. European Journal of Special Needs Education, 24, 337-354, http://dx.doi.org/10.1080/08856250903223021.

Musser, E. H., Bray, M. A., Kehle, T. J., \& Jenson, W. R. (2001). Reducing disruptive behaviors in students with serious emotional disturbance. School Psychology Review, 30, 294-305.

Muthén, L. K., \& Muthén, B. O. (1998-2012). Mplus user's guide (7th ed.) Los Angeles, CA: Author.

National Council of Welfare, Minister of Public Works and Government Services Canada (2004). Income for living? National Council of Welfare Report No. 24 (Retrieved from http://www .sixthestate.net/docs/welfare/incomeforliving.pdf)

Offord, D. R., \& Bennett, K. J. (1994). Conduct disorder: Long-term outcomes and intervention effectiveness. Journal of the American Academy of Child \& Adolescent Psychology, 33, 1069-1078.

Olds, D. L., Robinson, J. A., O’Brien, R., Luckey, D. W., Pettitt, L. M., Henderson, C. R., Jr., et al. (2002). Home visiting by paraprofessionals and by nurses: A randomized, controlled trial. Pediatrics, 110, 486-496.

Owens, J. S., Murphy, C. E., Richerson, L., Girio, E. L., \& Himawan, L. K. (2008). Science to practice in underserved communities: The effectiveness of school mental health programming. Journal of Clinical Child and Adolescent Psychology, 37, 434-447.

Patterson, G. R. (1977). Families: Applications of social learning to family life. Rev. ed. Champaign, IL: Research Press.

Peixoto, J. L. (1987). Hierarchical variable selection in polynomial regression models. The American Statistician, 41, 311-313.

Pfiffner, L. J., \& McBurnett, K. (1997). Social skills training with parent generalization: Treatment effects for children with attention deficit disorder. Journal of Consulting and Clinical Psychology, 65, 749-757.

Ramey, C. T., \& Ramey, S. L. (1998). Early intervention and early experience. American Psychologist, $53,109-120$.

Ray, K. P., Skinner, C. H., \& Watson, T. S. (1999). Transferring stimulus control via momentum to increase compliance in a student with autism: A demonstration of collaborative consultation. School Psychology Review, 28, 622-628.

Sanders, M. R. (1999). Triple P-Positive Parenting Program: Towards an empirically validated multilevel parenting and family support strategy for the prevention of behavior and emotional problems in children. Clinical Child and Family Psychology Review, 2, 71-90.

Sanders, M. R., Cann, W., \& Markie-Dadds, C. (2003). Why a universal population-level approach to the prevention of child abuse is essential. Child Abuse Review, 12, 145-154.

Sheridan, S. M. (2004). Parent competence in problem solving scale. Unpublished scale.

Sheridan, S. M. (2010). The tough kid social skills book. Eugene, OR: Pacific Northwest Publishing. 
Sheridan, S. M., Bovaird, J. A., Glover, T. A., Garbacz, S. A., Witte, A., \& Kwon, K. (2012). A randomized trial examining the effects of conjoint behavioral consultation and the mediating role of the parent-teacher relationship. School Psychology Review, 41, 23-46.

Sheridan, S. M., Clarke, B. L., Knoche, L. L., \& Edwards, C. P. (2006). The effects of conjoint behavioral consultation in early childhood settings. Early Education and Development, 17, 593-618.

Sheridan, S. M., Eagle, J. W., Cowan, R. J., \& Mickelson, W. (2001). The effects of conjoint behavioral consultation: Results of a four-year investigation. Journal of School Psychology, 39, 361-385.

Sheridan, S. M., Eagle, J. W., \& Doll, B. (2006). An examination of the efficacy of conjoint behavioral consultation with diverse clients. School Psychology Quarterly, 21, 396-417.

Sheridan, S. M., \& Kratochwill, T. R. (1992). Behavioral parent-teacher consultation: Conceptual and research considerations. Journal of School Psychology, 30, 117-139.

Sheridan, S. M., \& Kratochwill, T. R. (2008). Conjoint behavioral consultation: Promoting family-school connections and interventions. New York, NY: Springer.

Sheridan, S. M., Kratochwill, T. R., \& Elliott, S. N. (1990). Behavioral consultation with parents and teachers: Delivering treatment for socially withdrawn children at home and school. School Psychology Review, 19, 33-52.

Sheridan, S. M., Swanger-Gagné, M., Welch, G. W., Kwon, K., \& Garbacz, S. A. (2009). Fidelity measurement in consultation: Psychometric issues and preliminary examination. School Psychology Review, 38, 476-495.

Sheridan, S. M., Warnes, E. D., Woods, K. E., Blevins, C. A., Magee, K. L., \& Ellis, C. (2009). An exploratory evaluation of conjoint behavioral consultation to promote collaboration among family, school, and pediatric systems: A role for pediatric school psychologists. Journal of Educational and Psychological Consultation, 19, 106-129.

Simpson, G. A., Cohen, R. A., Pastor, P. N., \& Reuben, C. A. (2008). Use of mental health services in the past 12 months by children aged 4-17 years: United States, 2005-2006 (NCHS Data Brief, No. 8). Hyattsville, MD: National Center for Health Statistics.

Spiegelhalter, D. J., Best, N. G., Carlin, B. P., \& van der Linde, A. (2002). Bayesian measures of model complexity and fit (with discussion). Journal of the Royal Statistical Society, Series B: Statistical Methodology, 64, 583-639.

Stormshak, E. A., Bierman, K. L., McMahon, R. J., \& Lengua, L. J. (2000). Parenting practices and child disruptive behavior problems in early elementary school. Journal of Clinical Child Psychology, 29, 17-29.

Stormshak, E. A., Connell, A., \& Dishion, T. J. (2009). An adaptive approach to family-centered intervention in schools: Linking intervention engagement to academic outcomes in middle and high school. Prevention Science, 10, 221-235, http://dx.doi.org/10.1007/x1121-009-0131-3.

Swanger-Gagné, M., Garbacz, S. A., \& Sheridan, S. M. (2009). Intervention implementation integrity within conjoint behavioral consultation: Strategies for working with families. School Mental Health, 1, 131-142.

Taylor, T. K., \& Biglan, A. (1998). Behavioral family interventions for improving childrearing: A review of the literature for clinicians and policy makers. Clinical Child and Family Psychology Review, $1,41-60$.

Thompson, L., Lobb, C., Elling, R., Herman, S., Jurkidwewicz, T., \& Helluza, C. (1997). Pathways to family empowerment: Effects of family-centered delivery of early intervention services. Exceptional Children, 64, 99-113. 
U.S. Department of Health and Human Services (1999). Mental health: A report of the surgeon general. Rockville, MD: U.S. Public Health Service (Retrieved from http://profiles.nlm.nih.gov/ps/ retrieve/ResourceMetadata/NNBBHS)

U.S. Public Health Service (2000). Report of the surgeon general's conference on children's mental health: A national action agenda (Stock No. 017-024-01659-4). Washington, DC: U.S. Department of Health and Human Services (Retrieved from http://www.surgeongeneral.gov/cmh/childreport.htm)

Walker, H. M., \& Severson, H. H. (1990). Systematic screening for behavior disorders (SSBD): User's guide and administration manual. Longmont, CO: Sopris West.

Webster-Stratton, C., \& Hancock, L. (1998). Training for parents of young children with conduct problems: Content, methods, and therapeutic processes. In C. E. Schaefer, \& J. M. Briesmeister (Eds.), Handbook of parent training (pp. 98-152). New York, NY: John Wiley \& Sons.

Weiner, R., Sheridan, S. M., \& Jenson, W. R. (1998). Effects of conjoint behavioral consultation and a structured homework program on math completion and accuracy in junior high students. School Psychology Quarterly, 13, 281-309 (Panel 3: Noncompliance). 